\title{
Initial and long-term results of coronary angioplasty and coronary bypass surgery in patients of 75 or older
}

\author{
Hans Bonnier, Cornelis de Vries, Rolf Michels, Mamdouh El Gamal
}

\begin{abstract}
Objective-To evaluate clinical outcome after percutaneous transluminal coronary angioplasty (PTCA) or coronary artery bypass grafting (CABG) in patients of 75 or older who underwent either procedure between 1980 and 1987. Subjects-93 patients aged 75-89 with angina pectoris class III-IV (Canadian Cardiovascular Society) who underwent PTCA and 81 patients aged 75-84 with angina class III-IV who underwent CABG. Follow up was 8.2 years in the PTCA group and 8.3 years in the CABG group.
\end{abstract}

Main outcome measures-In-hospital complications and survival at follow up.

Results-Primary success rate for PTCA was $84 \%$ (78/93). Two patients died, two had emergency CABG, three had a myocardial infarction, and one had a cerebrovascular accident. PTCA failed in seven patients (five underwent elective CABG and two were treated conservatively). Median hospital stay was $4 \cdot 3$ days. Primary success rate for CABG was $63 \%(53 / 81)$. Six patients died, two had a cerebrovascular accident, eight had a myocardial infarction, 10 had a rethoracotomy, and four the adult respiratory distress syndrome. Median hospital stay was $14 \cdot 2$ days. In the PTCA group during follow up eight patients died, three had a non-fatal myocardial infarction, two had elective CABG, 10 had repeat PTCA, and four had recurrence of angina. Sixty four patients were free of angina (69\%). In the CABG group during follow up eight patients died, one had a non-fatal myocardial infarction, six had PTCA, and three had recurrence of angina. Fifty seven patients were free of angina AP (70\%). Actuarial survival after 10 years was $92 \%$ for PTCA and $91 \%$ for CABG. Conclusions-PTCA is safe in elderly patients. The complication rate is lower and hospital stay significantly shorter compared with CABG ( $<<0.05)$. Longterm follow up showed no significant difference between PTCA and CABG.

(Br Heart f 1993;70:122-125)

The general population is aging and the percentages and numbers of patients aged 75 or older are increasing. In this population a conservative approach is often chosen for those with ischaemic heart disease. When symptoms are not adequately alleviated, however, options for revascularisation should be considered. Several reports have documented the efficacy of percutaneous transluminal coronary angioplasty (PTCA) in elderly patients, ${ }^{1-18}$ but coronary artery bypass grafting (CABG) can also be performed in this group with increasing safety. ${ }^{18-28}$ In this observational study we report our experience between 1980 and 1987 in patients of 75 and older who underwent PTCA or CABG.

\section{Patients and methods}

Between September 1980 and December 1987, 3142 patients underwent PTCA in our institution. Ninety three were 75 or older (3\%). In the same period 3657 patients underwent CABG, of whom $81(2 \%)$ were 75 or older. Table 1 summarises the clinical characteristics of the patients.

\section{PROCEDURES}

PTCA was performed via the femoral artery in $98 \%$ of cases. In the majority $(72 \%)$ an over the wire balloon system was used. Angioplasty was considered successful when the stenosis was reduced to less than $50 \%$ of the luminal diameter, without major complications (myocardial infarction, cerebrovascular accident, emergency CABG, or death). Complete revascularisation was not necessarily the aim.

Table 1 Clinical characteristics of 174 patients of 75 or older who underwent PTCA or CABG. Values are numbers of patients unless stated otherwise

\begin{tabular}{|c|c|c|}
\hline & $P T C A(n=93)$ & $C A B G(n=81)$ \\
\hline Men & 54 & 53 \\
\hline Women & 39 & 28 \\
\hline Mean age (years) & 80 & 77 \\
\hline \multicolumn{3}{|l|}{ Smoker: } \\
\hline Former & 17 & 14 \\
\hline Current & 37 & 31 \\
\hline Hypertension & 47 & 40 \\
\hline Diabetes & 5 & 3 \\
\hline \multicolumn{3}{|l|}{ Angina (CCS class): } \\
\hline 0 & - & - \\
\hline I & - & - \\
\hline II & 0 & 2 \\
\hline III & 43 & 37 \\
\hline IV & 50 & 42 \\
\hline \multicolumn{3}{|l|}{ Previous: } \\
\hline Myocardial infarction & 36 & 30 \\
\hline CABG & 9 & 13 \\
\hline \multicolumn{3}{|l|}{ No of diseased vessels: } \\
\hline 1 & 4 & 3 \\
\hline 2 & 10 & 16 \\
\hline 3 & 79 & 62 \\
\hline \multicolumn{3}{|l|}{ Left ventricular ejection } \\
\hline$>45$ & 69 & 62 \\
\hline $25-45$ & 22 & 18 \\
\hline$<25$ & 2 & 1 \\
\hline
\end{tabular}

CCS, Canadian Cardiovascular Society.

Department of
Cardiology, Catharina
Hospital, Eindhoven,
The Netherlands
H Bonnier
C de Vries
R Michels
M El Gamal
Correspondence to:
Dr Hans Bonnier,
Department of Cardiology,
Catharina Hospital, Postbox
1350, 5602 ZA Eindhoven,
The Netherlands.
Accepted for publication
22 December 1992


Table 2 Extent of procedure in patients who underwent $P T C A$ or $C A B G$. Values are numbers (percentages) of patients

\begin{tabular}{lll}
\hline No of vessels/anastomosis & $P T C A(n=93)$ & $C A B G(n=81)$ \\
\hline 1/Distal & $67(72)$ & $3(4)$ \\
2/Distal & $23(25)$ & $15(19)$ \\
3/Distal & $3(3)$ & $12(15)$ \\
4/Distal & - & $51(62)$ \\
\hline
\end{tabular}

In patients undergoing $\mathrm{CABG}$, however, complete revascularisation was performed if possible. Cardiopulmonary bypass with moderate hypothermia and cristalloid cardioplegia was used.

\section{STATISTICAL ANALYSIS}

Continuous variables are expressed as medians (SD). Student's $t$ tests were performed to determine whether there was a significant difference between mean values.

\section{Results}

In total 122 vessels were dilated in the PTCA group: the left anterior descending artery or a graft to the left anterior descending artery in 66 patients $(54 \%)$, the left circumflex coronary artery in $24(20 \%)$, the right coronary artery in $22(18 \%)$, and the diagonal branch in seven (6\%). An unprotected left main stem was dilated in three patients $(2 \%)$. These three patients had class IV angina and were unsuitable candidates for CABG. Table 2 summarises the extent of the procedure in patients who underwent PTCA or CABG. One vessel was dilated in 67 patients $(72 \%)$, two vessels in $23(25 \%)$, and three vessels in three $(3 \%)$. In the CABG group three patients $(4 \%)$ had a single distal anastomosis, $15(19 \%)$ had two distal anastomoses, 12 $(15 \%)$ had three, and $51(62 \%)$ had four or more.

Complete revascularisation was performed more frequently in the CABG group than in the PTCA group, in whom only the culprit lesion was dilated in the majority of cases. PTCA was successful in 78 out of 93 patients (84\%). It was impossible to cross the lesion in seven patients: five of them underwent elective CABG and two were treated conservatively.

Table 3 summarises the complications in hospital after the two procedures. Two patients died in the PTCA group. One patient underwent salvage PTCA while in cardiogenic shock after myocardial infarction; the stenosis was adequately dilated, but the

Table 3 Complications in hospital after PTCA and $C A B G$. Values are numbers (percentages) of patients unless stated otherwise

\begin{tabular}{|c|c|c|}
\hline & $\begin{array}{l}P T C A \\
(n=93)\end{array}$ & $\begin{array}{l}C A B G \\
(n=81)\end{array}$ \\
\hline $\begin{array}{l}\text { Deaths } \\
\text { Emergency CABG } \\
\text { Carebrovascular accident } \\
\text { Myocardial infarction } \\
\text { Rethoracotomy } \\
\text { Prolonged ventilation } \\
\text { Median hospital stay (days) (range) }\end{array}$ & $\begin{array}{l}2 \\
2 \\
1 \\
3 \\
- \\
-4 \cdot 3(2-15)\end{array}$ & $\begin{array}{l}6^{\star} \\
2 \\
8 \\
10 \\
4 \\
14 \cdot 2(8-53)\end{array}$ \\
\hline Survival in hospital & $91(96)$ & $75(92)$ \\
\hline
\end{tabular}

^Four patients underwent emergency CABG after complications of coronary angiography performed elsewhere. patient died within 24 hours from progressive shock. The other patient developed dissection of the left main coronary artery, induced by the guiding catheter, and died during the procedure. Two patients underwent emergency CABG after failure of PTCA without complications. One patient had a cerebrovascular accident but recovered without residual symptoms and three patients suffered a myocardial infarction in the first 24 hours after PTCA. The survival rate in hospital for the PTCA group was $96 \%$ (91 patients). The median hospital stay was $4 \cdot 3$ days (2-15).

CABG was uneventful in 53 out of 81 patients $(63 \%)$. Deaths of six patients $(7 \%)$ were all related to the procedure. Four patients died during emergency surgery from evolving myocardial infarction as a result of complications during coronary angiography that had been performed elsewhere. Two other patients sustained a myocardial infarction during the operation and died on the second and third day after the procedure. In addition, 24 patients developed non-fatal complications within 30 days, including CVA (two patients), and recovered uneventfully. Eight patients had an uncomplicated myocardial infarction, 10 required rethoracotomy because of excessive bleeding, and four required prolonged ventilation (more than three days) for the adult respiratory distress syndrome. Hospital survival was 92\% (75 patients). The median hospital stay was $14 \cdot 2$ days $(8-53)$.

\section{LONG TERM FOLLOW UP}

Follow up was complete in all patients up to June 1991. Information was obtained from the referring physician, from patients at out patient visits, or by telephone. Table 4 shows the late outcome in the patients.

In the PTCA group mean follow up was $8 \cdot 2$ years (3.5-10.9). Actuarial survival was $92 \%$ after 10 years. There were eight late deaths: two sudden cardiac deaths after three and six years and six non-cardiac deaths from cancer. Three patients had a non-fatal myocardial infarction. Elective CABG was

Table 4 Outcome in patients of 75 or older after PTCA or $C A B G$. Values are numbers (percentages) of patients unless stated otherwise

\begin{tabular}{|c|c|c|}
\hline & $P T C A(n=93)$ & $C A B G(n=81)$ \\
\hline \multicolumn{3}{|l|}{ Death: } \\
\hline In hospital & 2 & $6 \star$ \\
\hline \multicolumn{3}{|l|}{ Late: } \\
\hline Cardiac & 2 & 3 \\
\hline Non-cardiac & & \\
\hline \multirow{2}{*}{\multicolumn{3}{|c|}{$\begin{array}{l}\text { Survival } \\
\text { Actuarial survival after }\end{array}$}} \\
\hline & & \\
\hline \multicolumn{3}{|l|}{ Myocardial infarction: } \\
\hline Non-fatal & 3 & 1 \\
\hline $\begin{array}{l}\text { None } \\
\text { Nective }\end{array}$ & 80 & 66 \\
\hline Elective CABG & 2 & - \\
\hline \multicolumn{3}{|l|}{ No myocardial infarction } \\
\hline Repeat PTCA & 10 & - \\
\hline PTCA & - & 6 \\
\hline $\begin{array}{l}\text { No myocardial infarction, } \\
\text { CABG, or PTCA }\end{array}$ & 68 & 60 \\
\hline Recurrence of angina & 4 & 3 \\
\hline $\begin{array}{l}\text { No myocardial infarction, } \\
\text { CABG, PTCA, or angina }\end{array}$ & $64(70)$ & $57(76)$ \\
\hline
\end{tabular}

${ }^{\star}$ Four patients underwent emergency CABG after complications of coronary angiography performed elsewhere. 
performed in two patients because of recurrence of angina pectoris, and repeat PTCA was performed in 10 patients. Thus in the PTCA group 68 patients $(76 \%)$ had long term event free survival. Four of these patients had class II-III angina pectoris according to the Canadian Cardiovascular Society's definitions, and this was treated conservatively. Therefore 64 patients $(70 \%$ of the initially surviving group) were free of angina.

In the CABG group mean follow up was $8 \cdot 3$ years $(3 \cdot 5-11 \cdot 2)$. Actuarial 10 year survival was $91 \%$ (excluding the four early deaths during emergency surgery). There were eight late deaths (11\%): one patient died after 5.4 years from myocardial infarction, two patients died suddenly 2.4 and 6.8 years after operation, and five patients died of cancer. Only 1 patient had a non-fatal myocardial infarction. Elective PTCA was performed in six of the patients who had had CABG because of recurrence of angina pectoris. Thus in the CABG group 60 patients $(80 \%)$ had event free long term survival. Three of these patients had class II-III angina pectoris, which was treated conservatively. Thus 57 patients (76\% of the initial group) survived free of angina. The figure shows total survival calculated by the Kaplan-Meier method $^{29}$ for all patients of 75 or older who underwent PTCA or CABG. The four patients who were referred to our institution for emergency CABG after complications during coronary angiography elsewhere and died are not included. There was no significant difference between the two groups.

\section{Discussion}

Patients of 75 or older form a considerable and rapidly growing proportion of the population. In 1995 the number of elderly citizens $(>65)$ in The Netherlands will increase to two million, and it is calculated that in 2030 one million Dutch citizens will be 75 or older.

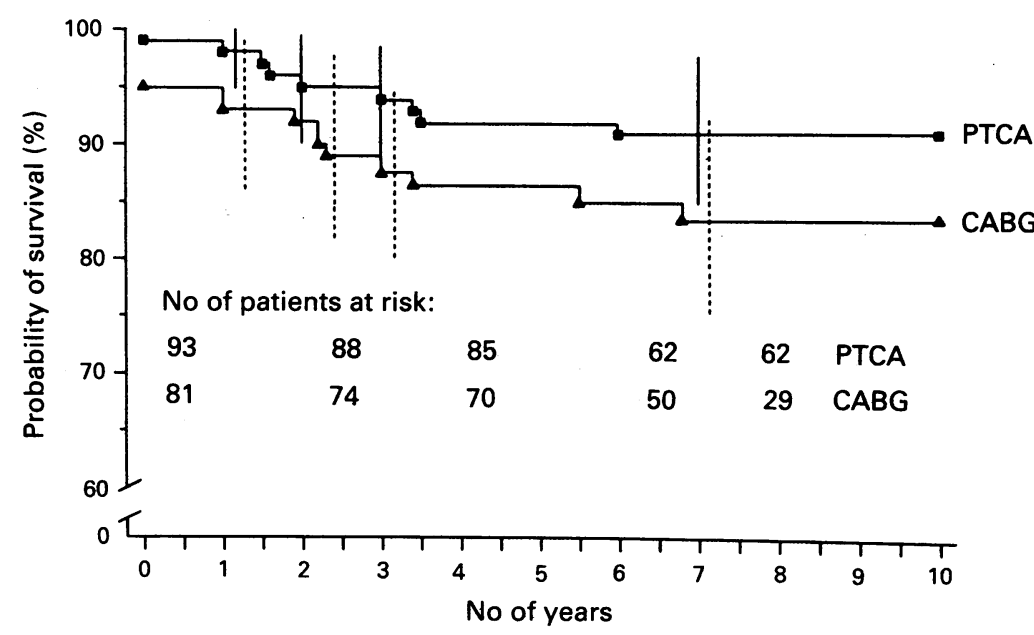

Kaplan-Meier curve of total survival time for patients of 75 or older who underwent PTCA or CABG. Vertical lines are $95 \%$ confidence intervals. The four patients who were referred to our institution for emergency bypass surgery after complications of coronary angiography and died during the procedure are not included in the analysis.
Cardiovascular disease remains the main cause of morbidity and mortality in this age group,,$^{30}$ and an increasing number of elderly patients unresponsive to medical treatment for angina pectoris will be referred for PTCA or CABG. In this group CABG is associated with an increased mortality and morbidity. ${ }^{18-28}$ In a recent review of the influence of age on the results of coronary artery surgery, Weintraub et al reported the highest mortality in patients of 80 or older, followed by those of 70-79. ${ }^{27}$ Wound infection and neurological events were higher than in younger patients. Several reports indicate that the results of PTCA in elderly patients are comparable to those obtained in younger patients, ${ }^{31}$ although other authors report lower success rates and increased morbidity. ${ }^{12}$ Thus PTCA may be an attractive alternative to surgery. ${ }^{1-1732}$

Our results for both PTCA and CABG are similar. The rate of complications tended to be higher in the CABG group, and the stay in hospital was also significantly longer. Late outcome was excellent in both groups, although there was a trend towards more cardiac events necessitating repeated interventions in the PTCA group to achieve the same late outcome. Interestingly, mortality during follow up in both groups was mainly from cancer and not coronary artery disease. We also observed that dilating the culprit lesion in most patients who had PTCA was sufficient to achieve a similar late outcome as complete revascularisation in patients who had CABG.

A point of criticism of our study is how patients were selected. The procedures were not randomly assigned, and there is no explanation why PTCA was done in a certain cohort of patients and CABG in another (indication bias).

In conclusion, PTCA and CABG in patients of 75 or older have low complication rates. In elderly patients dilatation of the culprit lesion often provided adequate symptomatic relief in the majority of patients. The complication rate for PTCA was lower and the hospital stay was shorter compared with CABG. These observations suggest that PTCA is preferable to CABG when the culprit lesion is suitable for PTCA. If the culprit lesion is not identified or unsuitable for PTCA, CABG can be performed with an acceptable risk.

We thank the cardiopulmonary surgeons of the Catharina We thank the cardiopulmonary surgeons of the Catharina P N Hendel, Y A Mashour, J P Schönberger) for allowing us to use their data.

1 Mock MB, Holmes DR Jr, Vlietstra RE, Gersh BJ, Detre $\mathrm{KM}$, Kelsey SF, et al. Percutaneous transluminal coronary angioplasty (PTCA) in the elderly patient: coronary angioplasty (PTCA) in the elderly patient: experience in the National Heart, Lung, and Blood Institute's PTCA Registry. $A m$ I Cardiol. 89-91C.

2 Kelsey SF, Miller DP, Holubkov R, Lu AS, Cowley MJ, Faxon DP, et al. Results of percutaneous transluminal coronary angioplasty in patients $\geq 65$ years of age (from the 1985 to 1986 National Heart, Lung, and Blood Institute's Coronary Angioplasty Registry). Am $\mathcal{F}$ Cardiol 1990;66:1033-8.

3 Raizner AE, Hust RG, Lewis J, Winter WL, Batty JW, Roberts R. Transluminal coronary angioplasty in the 
elderly. Am f Cardiol 1986;57:29-32.

4 Dorros G, Janke L. Percutaneous transluminal coronary angioplasty in patients over the age of 70 years. Cathet Cardiovasc Diagn 1986;12:223-39.

5 Simpfendorfer C, Raymond R, Schrader J, Badhwar K, Dorosti K, Franco I, et al. Early and long-term results of percutaneous transluminal coronary angioplasty in patients 70 years of age and older with angina. $A m \mathcal{F}$ patients 70 years of age
Cardiol $1988 ; 62: 959-61$.

6 Urban P, Fox K, Crean P, Shapiro L, Rickards A. Coronary balloon angioplasty for elderly patients with Coronary balloon angioplasty for elderly

7 Kitazume H, Kubo I, Iwama T, Ageishi Y, Suzuki A. Percutaneous transluminal coronary angioplasty for elderly patients. Fpn Circ $\mathcal{F} 1988 ; 52: 449-53$.

8 Mills TJ, Smith HC, Vlietstra RE. PTCA in the elderly: results and expectations. Geriatrics 1989;44:71-9.

9 Imburgia M, King TR, Soffer AD, Rich MW, Krone RJ, Salimi A. Early results and long-term outcome of percutaneous transluminal coronary angioplasty in patients aged 75 years or older. $A m \mathcal{F}$ Cardiol 1989;63:1127-9.

10 Holt GW, Sugrue DD, Bresnahan JF, Vlietstra RE, Bresnahan DR, Reeder GS, et al. Results of percutaneous transluminal coronary angioplasty for unstable angina pectoris in patients 70 years of age and older. Am 7 Cardiol 1988;61:994-7.

11 Lee TC, Laramee LA, Rutherford BD, McConahay DR, Johnson WL Jr, Giorgi LV, et al. Emergency percutaneous transluminal coronary angioplasty for acute neous transluminal coronary angioplasty for acute myocardial infarction in patients

12 Kern MJ, Deligonul U, Galan K, Zelman R, Gabliani G, Bell ST, et al. Percutaneous transluminal coronary angioplasty in octogenarians. Am $\mathcal{f}$ Cardiol 1988;61: 457-8.

13 Hartzler GO, Rutherford BD, McConahay DR, Johnson WL, Giorgi LV. "High-risk" percutaneous transluminal coronary angioplasty. Am $\mathcal{f}$ Cardiol 1988;61:33-7G.

14 Rich JJ, Crispino CM, Saporito J, Domat I, Cooper WM. Percutaneous transluminal coronary angioplasty in patients 80 years of age and older. Am 7 Cardiol 1990;65:675-6.

15 Rizo-Patron C, Hamad N, Paulus R, Garcia J, Beard E. Percutaneous transluminal coronary angioplasty in octogenarians with unstable angina $\mathrm{Am} \mathcal{F}$ Cardiol 1990;66:857-8.

16 Jeroudi MO, Kleiman NS, Minor ST, Hess KR, Lewis $\mathrm{JM}$, Winters WL Jr, et al. Percutaneous transluminal coronary angioplasty in octogenarians. Ann Intern Med coronary angioplast

17 Kowalchuk GJ, Siu SC, Lewis SM. Coronary artery disease in the octogenarian: angiographic spectrum and
suitability for revascularization. Am $\mathcal{F}$ Cardiol 1990;66: suitability
18 Myler RK, Webb JG, Nguyen KPV, Shaw RE Schechtmann NS, Bashour TT, et al. Coronary angioplasty in octogenarians: comparisons to coronary bypass surgery. Cathet Cardiovasc Diagn 1991;23:3-9.

19 Loop FD, Lytle BW, Cosgrove DM, Goormastic M, Taylor PC, Golding LAR, et al. Coronary artery bypass graft surgery in the elderly. Indications and outcome. Cleve Clin 7 Med 1988;55:23-34.

20 Rich MW, Keller AI, Schechtman KB, Marshall WG Jr, Kouchoukos NT. Morbidity and mortality of coronary bypass surgery in patients 75 years of age or older. Ann bypass surgery in patients 75 .
Thorac Surg 1988;46:638-44.

21 Acinapura AJ, Rose DM, Cunningham JN, Jacobwitz IJ, Kramer MD, Zisbrod Z. Coronary bypass in septuagenarians. Analysis of mortality and morbidity. Circulatio 1988;78:1179-84

22 Tsai T, Chaux A, Kass RM, Gray RJ, Matloff JM. Aortocoronary bypass surgery in septuagenarians. $\mathcal{f}$ Cardiovasc Surg (Torino) 1989;30:364-8.

23 Morgan JM, Gray HH, Clague JC, Gibson DG. Coronary arterial surgery in the elderly: its effect in the relief of angina. Int $\mathcal{F}$ Cardiol 1989;23:327-33.

24 Gersh BJ, Kronmal RA, Frye RL, Schaff HV, Ryan TJ, Gosselin AJ, et al. Coronary angiography and coronary artery bypass surgery. Morbidity and mortality in patients age 65 years or older. A report from the coropatients age 65 years or older. A report from the coro-

25 Hochberg MS, Levine FH, Daggett WM, Akins CW, Austen WG, Buckley MJ. Isolated coronary artery Austen WG, Buckley $M$ J. Isolated coronary artery bypass grafting in patients seventy years of age or older.
Early and late results. $\mathcal{f}$ Thorac Cardiovasc Surg Early and late

26 Elayda MA, Hall RJ, Gray AG, Mathur VS, Cooley DA. Coronary revascularization in the elderly patient. $\mathcal{F} \mathrm{Am}$ Coll Cardiol 1984;3:1398-40

27 Weintraub WS, Craven JM, Cohen CL, Jones EL, Guyton RA. Influence of age on results of coronary artery surgery. Circulation 1991;84:226-35.

28 Nauheim KS, Kern MJ, McBride LR, et al. Coronary artery bypass surgery in patients aged 80 years or older. Am f Cardiol 1987;59:804-7.

29 Machin D, Gardner MJ. Calculating confidence intervals for survival time analysis. BMF 1988;296:1369-71.

30 Simons LA. Epidemiologic considerations in cardiovascular diseases in the elderly: international comparisons and trends. Am $\mathcal{F}$ Cardiol 1989;63:5-8H.

31 Webb JG, Myler RK, Shaw RE, et al. Coronary angioplasty in young adults. Initial results and late outcome. $\mathcal{f}$ Am Coll Cardiol 1990;16:1569-74.

32 Bal ET, Berg ten JM, Tjon Joe Gin RM, Ernst JMPG, Mast EG, Ascoop CAPL, et al. Percutaneous translumiMast EG, Ascoop CAPL, et al. Percutaneous transluminal coronary angioplasty in patients 75 years of age and
older: initial results and long-term clinical follow up. Netherlands fournal of Cardiology 1991;4:160-4. 